\title{
Article \\ Effects of intercropping on soil fractal dimension and physico- chemical properties in the karst areas
}

\author{
Qinqin Xua ${ }^{1,2}$, Kangning Xiong ${ }^{1,2^{*}}$, Yongkuan $\mathrm{Chi}^{1,2}$ \\ 1 School of Karst Science, Guizhou Normal University, Guiyang, P.R. China; 19010170416@gznu.edu.cn (Q.Q.- \\ X.); xiongkn@gznu.edu.cn (K.N.-X.), 201907002@gznu.edu.cn (Y.K.-C.) \\ 2 State Engineering Technology Institute for Karst Desertfication Control, Guiyang, P.R. China. \\ 19010170416@gznu.edu.cn (Q.Q.-X.); xiongkn@gznu.edu.cn (K.N.-X.), 201907002@gznu.edu.cn (Y.K.-C.) \\ * Corresponding author: xiongkn@gznu.edu.cn
}

\begin{abstract}
Suitable soil structure and nutrient security are important for plant growth and development, characteristics of soil fractal dimension and distribution of physical and chemical properties and their interactions play an important role in studying the stability of soil structure and water and fertilizer cycles. As a sustainable management model, intercropping has positive benefits for erosion control, spatial optimization of resources, as well as improving system productivity. The effects of four intercropping methods on soil fractal dimension and physicochemical properties were investigated by intercropping Salvia miltiorrhiza with forage and S. miltiorrhiza with forest under typical karst rock desertification habitats in Guizhou. The results showed that soil nutrient content of intercropping was significantly higher than that of monoculture, the organic carbon content of soil grown under forest is higher than other treatments, and there was a non-significant change in soil water content of intercropping compared with monoculture. The soil fine-grained matter of intercropping was significantly higher than that of monoculture, while the soil fractal dimension showed a tendency to become larger with the increase of fine-grained matter. The intercropping planting, due to its component types and spatial and temporal configurations, leads to differences in soil water and fertilizer interactions, which can be combined with other ecological restoration measures to optimize the composite model and jointly promote the restoration and development of ecologically fragile areas.
\end{abstract}

Keywords: karst; intercropping; soil fractal dimension; soil physicochemical properties; soil nutrients

\section{Introduction}

Karst rock desertification is a land degradation process that occurs in subtropical humid and semi-humid areas, which belongs to a special type of desertification [1,2]. The area of karst in southern China, centered on the Guizhou plateau, is the largest and most concentrated contiguous karst ecologically fragile area in the world, with an area of more than $55 \times 104 \mathrm{~km} 2$, and it is also one of the most typical and complex karst development with the most abundant landscape types $[3,4]$. Driven by both natural factors and human activities, soil erosion, underground leakage, and the proliferation of rocky desertification areas are frequent, resulting in problems such as poor ecosystem stability and weak resistance to disturbance [5]. On the basis of modern technological innovation and the new concept of green development, agricultural management systems such as intercropping, crop set, crop rotation, forest-grain combination, forest-agriculture combination, and grain-grass combination have been developed one after another, especially intercropping and compound agroforestry management is more advocated by the majority of scholars, which realizes the diversification of cropping system and the high efficiency of resource utilization, which has various effects on preventing soil erosion, protecting biodiversity, 
improving soil fertility and protecting ecological environment, it is one of the important measures to solve the problems of food, environment and economic development in countries or regions with relatively scarce resources[6 8]. The uneven distribution of agricultural resources and environmental problems in the stone desertification areas of southwest China are not conducive to the development of large-scale mechanical scale agricultural production and operation methods, and the diverse and small habitats dominated by complex terrain make it easier to develop intensive green agriculture [9]. Although scientific measures to prevent and control stone desertification have been effective for a long time, with the continuous promotion of stone desertification management project, how to effectively build the integrity of community structure, enhance the stability and service function of ecosystem, balance the relationship between ecological environment and economic development, and further scientific and green prevention and control of stone desertification is still the key content of future work [10].

Fractal dimension not only characterizes the influence of soil particle distribution on soil structure and indicates soil quality and ecological environment [11,12], but also is an important indicator to characterize soil evolution process, which can be used to evaluate and monitor the effect of ecological restoration and vegetation recovery on soil quality and the effectiveness of stone desertification management [13]. Soil particles, as the basic structural unit of soil, are closely related to the changes in soil structure and play an important role in the improvement of soil aeration, permeability, adhesion and expansion and contraction [14], and in general, the higher the content of fine-grained material in the soil, the more uniform the soil structure and the higher the fractal dimension, and there is a significant positive correlation between the fractal dimension and soil nutrients, which has It is an important indicator for the prevention and management of stone desertification. In this paper, the heterogeneity of soil fractal characteristics and physicochemical property distribution is used to study the influence of intercropping on soil erosion and degradation, and to analyze the conservation function of intercropping in stone desertification ecosystem, which is important for guiding the protection and restoration of stone desertification ecosystem and efficient crop production, in order to promote the application of agroforestry technology and the water and soil conservation in ecologically fragile areas. It is expected to provide a theoretical basis for the application of agroforestry technology and the construction of soil and water conservation and ecological environment in ecologically fragile areas.

\section{Materials and Methods}

\subsection{Overview of the location of the study area}

The test site is located in Shibing County, Qiandongnan Miao and Dong Autonomous Prefecture, Guizhou Province, China (Figure 1), in the middle section of the Maoyang River of the Yuanjiang River system in the Yangtze River basin, which is a typical dolomite karst mountain canyon landform type [15]. The geomorphic evolution in the region is a rare structural system and evolutionary sequence of tropical and subtropical karst ascending development in the world. It located in the mountainous region of Qianzhong, with large topographic relief and elevation in the range of $486 \mathrm{~m} \sim 1869 \mathrm{~m}$, belongs to the central subtropical monsoonal humid climate zone, with warm winters and cool summers, four seasons like spring, annual average temperature of $16.5^{\circ} \mathrm{C}$, annual temperature difference of $20.2^{\circ} \mathrm{C}$, annual precipitation concentrated in the distribution of April-October. The total annual solar radiation is $9.26 \times 10^{6} \mathrm{Kw} \cdot \mathrm{m}^{-2}$, the lithology is thin fine-grained dolomite of the Cambrian Gaotai Formation, soils are mainly black lime soils with rich gravel content in some soils [16,17]. The climate is mild and humid, the topography is complex, the habitat types is diverse, and the region is rich in rare species represented by Taxus wallichiana, Amentotaxus argotaenia, Keteleeria pubescens, and Pseudotsuga sinensis, forming an ecosystem with typicality and specificity. Agricultural production is based on 
Oryza sativa, Zea mays, Nicotiana tabacum, Brassica napus, Capsicum annuum, Pseudostellaria heterophylla, S. miltiorrhiza and other crops are the main crops.

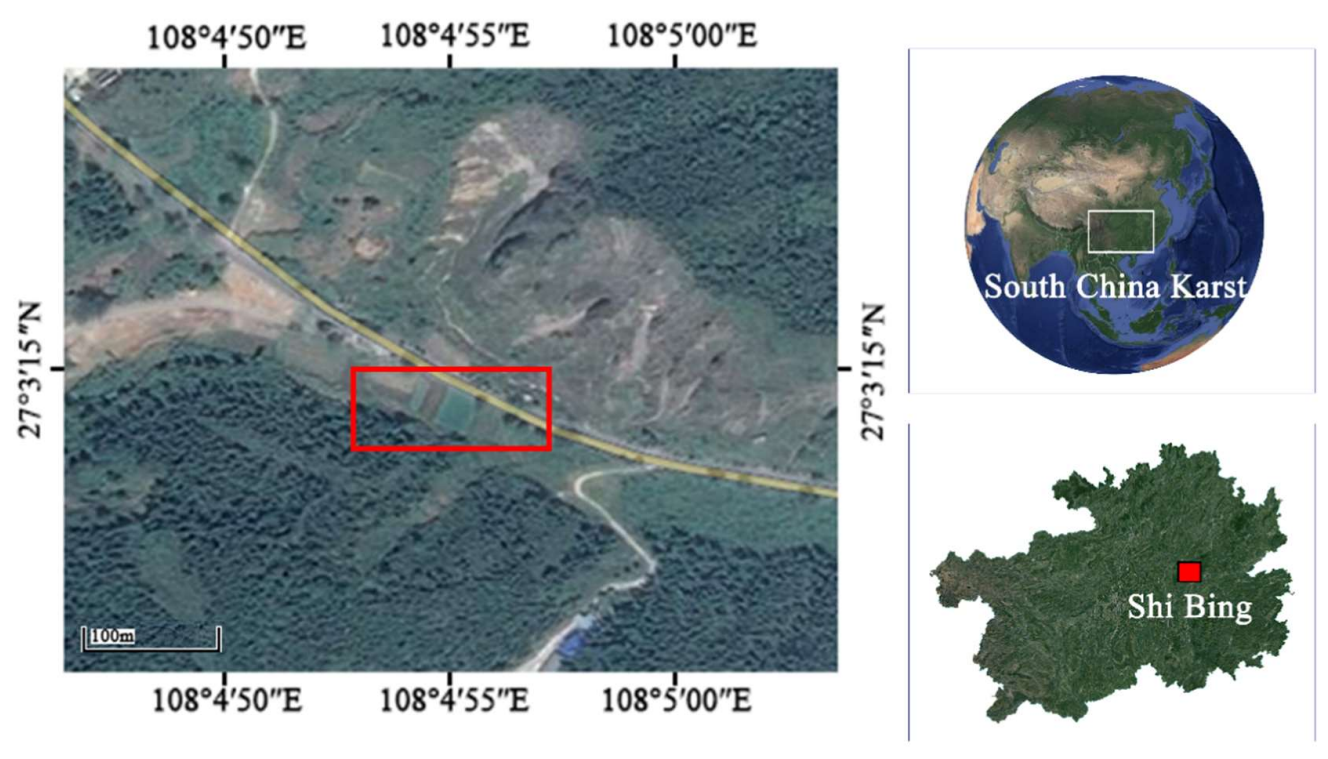

Figure 1. Study area and sample location information.

\subsection{Experimental design}

The experiment was carried out in five planting patterns in the same latitude, longitude, altitude and slope direction (Table 1), namely (Figure 2): S. miltiorrhiza monocrop, $S$. miltiorrhiza - Lolium perenne intercrop, S. miltiorrhiza-Medicago sativa intercrop, S. miltiorrhiza - Sophora japonica intercrop, S. miltiorrhiza - Lagerstroemia indica intercrop, each planting plot was $4 \mathrm{~m} \times 12 \mathrm{~m}$, and each pattern was replicated three times. S. miltiorrhiza was planted on March 23, 2020, using the monopoly method, with two rows of S. miltiorrhiza planted in each monopoly, with a monopoly width of $70 \mathrm{~cm}$, row spacing of $20 \mathrm{~cm}$ and plant spacing of $30 \mathrm{~cm}$. L. perenne and M. sativa were planted on March 23, 2020, using the strip sowing method, planted in the monopoly furrow, with four rows of forage grass planted in every other monopoly of S. miltiorrhiza, with a row spacing of $30 \mathrm{~cm}$, and the seeding quantity of L. perenne and $M$. sativa were $15 \mathrm{~kg} / \mathrm{hm}^{2}$. The planting time of landscape trees was advanced one year to March 23, 2019, and the planting spacing was $1.5 \mathrm{~m} \times 1.5 \mathrm{~m}$, and the spacing between $S$. miltiorrhiza, and landscape trees was $30 \mathrm{~cm}$, one monopoly of $S$. miltiorrhiza, and one row of landscape trees. The species of S. miltiorrhiza for trial was from Bozhou Wanfeng Chinese Medicine Technology Co., the L. perenne was Neptune perennial L. perenne, and the M. sativa species was Suntory. $134 \mathrm{~kg} / \mathrm{hm}^{2}$ of compost was uniformly tilled and applied before planting, and no tilling, irrigation and fertilizer application were carried out during the growth process. 

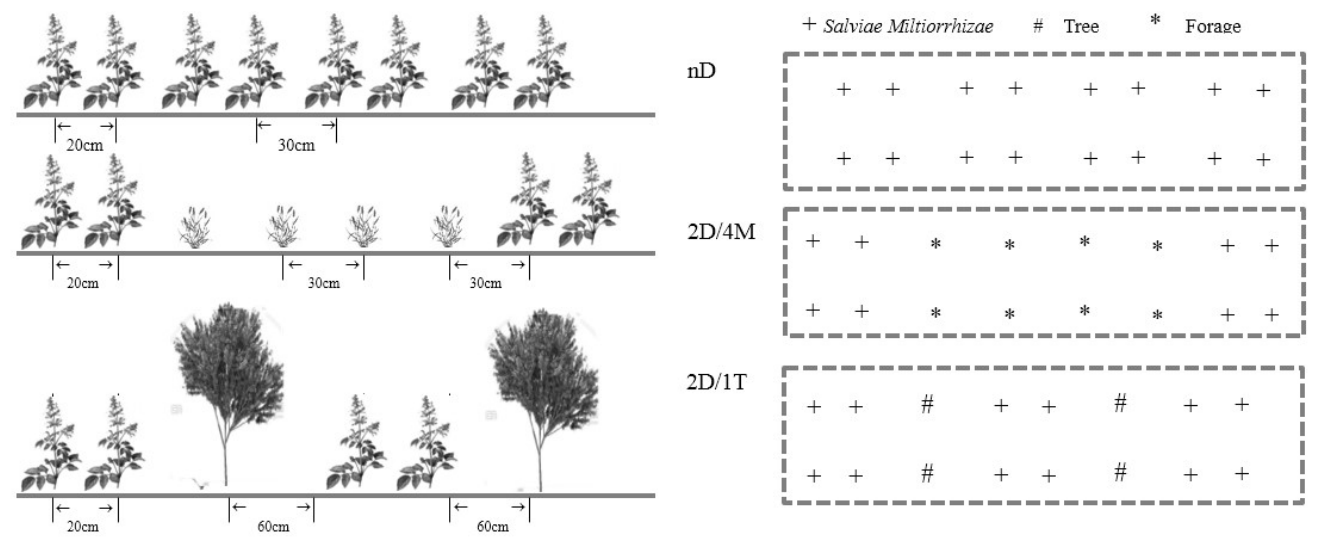

Figure 2. Planting diagram.

$\mathrm{nD}$ represents the number of rows of Danshen single crop; $2 \mathrm{D} / 4 \mathrm{M}$ represent two rows of Danshen intercropped with 4 rows of Forage; 2D/1T represent two rows of Danshen intercropped with 4 rows of landscape tree.

Table 1. Sampling point location and information.

\begin{tabular}{|c|c|c|c|c|c|c|}
\hline Treatment & longitude & latitude & Altitude/m & Aspect & Slope & slope \\
\hline Salvia miltiorrhiza $(\mathrm{CK})$ & $108.0812^{\circ}$ & $27.0543^{\circ}$ & $717.08 \mathrm{~m}$ & Sunny slope & Upslope & 11 \\
\hline Salvia miltiorrhiza - Lolium perenne (DM) & $108.0811^{\circ}$ & $27.0540^{\circ}$ & $716.88 \mathrm{~m}$ & Sunny slope & Upslope & 9 \\
\hline Salvia miltiorrhiza-Medicago sativa(DJ) & $108.0822^{\circ}$ & $27.0532^{\circ}$ & $718.85 \mathrm{~m}$ & Sunny slope & Middle slope & 7 \\
\hline Salvia miltiorrhiza - Sophora japonica(DB) & $108.0823^{\circ}$ & $27.0535^{\circ}$ & $719.89 \mathrm{~m}$ & Sunny slope & Upslope & 7 \\
\hline Salvia miltiorrhiza - Lagerstroemia indica $(\mathrm{DH})$ & $108.0824^{\circ}$ & $27.0537^{\circ}$ & $721.25 \mathrm{~m}$ & Sunny slope & Middle slope & 5 \\
\hline
\end{tabular}

\subsection{Sample analysis and determination method}

\subsubsection{Analysis of soil physical and chemical properties}

On October 24, 2020, the S-shaped random sampling method was adopted in four layers with sampling depths of $0-20 \mathrm{~cm}$, and the samples were repeated three times, mixed and brought back to the laboratory for natural air-drying, removing visible plant roots and gravels, passing through $0.15 \mathrm{~mm}$ and $2 \mathrm{~mm}$ soil sieves, and stored at room temperature. Soil capillary water holding capacity, soil saturated water content, capillary porosity and relative water content were determined by drying method and ring knife method. Soil organic carbon was determined by the potassium dichromate oxidation-external heating method, the change in the amount of dichromate ions before and after the organic carbon was oxidized, and the content of organic carbon (SOC) in the soil was calculated. Soil nitrate nitrogen and ammonium nitrogen were extracted by ISO standard method with potassium chloride solution, and the samples were measured on a continuous flow analyzer (SYSTEA, Italy) using $550 \mathrm{~nm}$ and $660 \mathrm{~nm}$ filters on the upper machine, respectively.

\subsubsection{Analysis of Soil Particles and Fractal Dimension}

Soil particle distribution was measured by hydrometer method to determine the volume content of soil particles at different particle sizes, according to the U.S. sand matter particle size classification standards, i.e. coarse sand $(0.2 \sim 2 \mathrm{~mm})$, fine sand $(0.02 \sim 0.2 \mathrm{~mm})$, powder $(0.002 \sim 0.02 \mathrm{~mm})$, and clay $(<0.002 \mathrm{~mm})$, and the volume percentage content of soil particles in each particle size range was calculated. Soil particle fractal dimension was calculated according to the soil fractal model characterized by the volume distribution of particle size proposed by Tyler and Wheatcrsft[18].

$$
\left(\frac{R_{i}}{R_{\max }}\right)^{3-D}=\frac{V\left(r<R_{i}\right)}{V_{T}}
$$




$$
\lg \left[\left(\frac{R_{i}}{R_{\max }}\right)^{3-D}\right]=\lg \left[\frac{V\left(r<R_{i}\right)}{V_{T}}\right]
$$

In equation (1): $r$ denotes the particle radius, $R_{i}$ denotes the $i$-th particle size in the particle size classification, $\mathrm{V}\left(\mathrm{r}<\mathrm{R}_{\mathrm{i}}\right)$ denotes the percentage volume of particles smaller than a certain particle size $\left(R_{i}\right)$, VT denotes the sum of the total soil particle volume, $R_{\max }$ denotes the maximum particle size in soil particles, and D is the fractal dimension of soil particle distribution. Both sides of the equation are taken logarithmically at the same time, and the scatter plot is made with the left side of equation (2) as the horizontal coordinate and the right side of equation (2) as the vertical coordinate, and the linear regression fitting equation and fitting coefficients are obtained according to the least squares method, and the slope of the fitted linear regression equation is equal to (3-D) in equation (2), so as to obtain the soil fractal dimension D of each sample.

\subsection{Statistics and Analysis}

One-way ANOVA, LSD multiple comparisons and Principal components analysis (PCA) were conducted using SPSS22.0 to analyze the significance of differences between different intercropping patterns and soil layers in terms of soil fractal dimension, soil particle distribution and soil carbon and nitrogen content test.

\section{Results}

\subsection{Study on the change of physical properties of soil by intercropping}

As shown in (Figure 3), the average contents of capillary water holding capacity, saturated water content, capillary porosity and relative water content of 0-20 cm soil depth were $20.89 \%$, 24.29\%, 34.28\% and $69.39 \%$, respectively. The saturated water content, capillary water holding capacity and capillary porosity content showed a decreasing trend with increasing soil depth, but the relative water content showed an increasing trend with increasing soil depth. Soil saturated water content was significantly different $(P<0.05)$ between the intercropping treatments and CK within $0 \sim 5 \mathrm{~cm}$ and $10 \sim 15 \mathrm{~cm}$ soil layers. The difference between DM treatment and CK treatment was not significant $(P>0.05)$ in the 5$10 \mathrm{~cm}$ soil layer, the highest content was in the DJ treatment. In the $15-20 \mathrm{~cm}$ soil layer, DB and $\mathrm{DH}$ treatments were not significantly different from $\mathrm{CK}(P>0.05)$. Soil relative water content differed in different soil depth ranges. The relative soil water content of intercropping was generally greater than that of monoculture. In the $0 \sim 5 \mathrm{~cm}$ soil layer, there is no significant difference in CK between DM and DJ treatments $(P>0.05)$. There is no significant difference between DJ treatment and CK in $5 \sim 10 \mathrm{~cm}, 10 \sim 15 \mathrm{~cm}$ soil layer $(P>0.05)$, while in 15 20 cm soil layer, there is no significant difference between DB treatment and CK $(P>0.05)$. Soil capillary porosity did not vary significantly among treatments, and was highest in the DB treatment in the $0-15 \mathrm{~cm}$ soil depth range and in the DH treatment in the 15-20 cm soil depth range. Non-significant differences existed between the intercropping treatments and $C K$ in the $0-20 \mathrm{~cm}$ soil depth range $(P>0.05)$. Soil capillary water holding capacity was highest in the CK treatment and lowest in the DJ treatment, as well as significant differences existed between the DJ treatment and CK, within the $0-5 \mathrm{~cm}$ soil depth $(P<0.05)$. There was no significant difference between DM treatment and $\mathrm{CK}$ within $5 \sim 10 \mathrm{~cm}$ soil layer $(P>0.05)$. Within the $10-15 \mathrm{~cm}$ soil layer, there were significant differences between both intercropping treatments and $C K$, while there were non-significant differences between all intercropping treatments $(P>0.05)$. Within the $15-20 \mathrm{~cm}$ soil layer, the significant difference existed between DM treatment and CK, with the lowest content in DM treatment. 

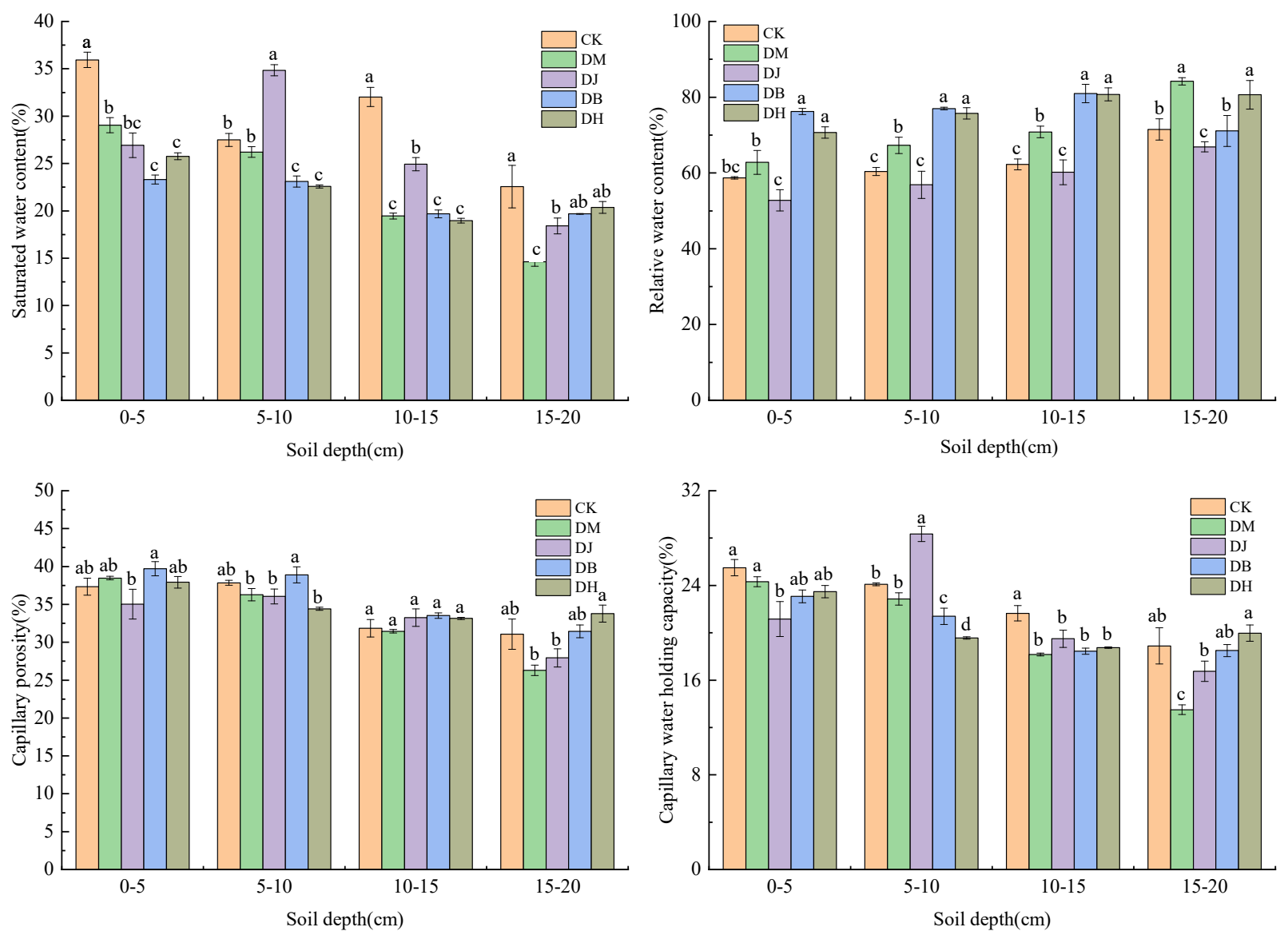

Figure 3. Comparison of soil physical properties with different treatments.

CK: Salvia miltiorrhiza monoculture; DM: Salvia miltiorrhiza - Lolium perenne intercropping mode; DJ: Salvia miltiorrhiza- Cichorium intybus intercropping mode; DB: Salvia miltiorrhiza - Trifolium repens intercropping mode; DH: Salvia miltiorrhiza - Lolium perenne intercropping mode. Different lowercase letters indicate significant differences $(P<0.05)$, the same below.

\subsection{Study on the change of soil carbon and nitrogen by intercropping}

The planting pattern had a significant effect on soil organic carbon distribution $(P<0.05)$. The soil organic carbon content was decreasing with the increase of soil depth. Intercropping treatment showed significantly higher soil organic carbon content than monoculture treatment in all soil depths(Figure 4). In the $0 \sim 5 \mathrm{~cm}, 10 \sim 15 \mathrm{~cm}$ and $15 \sim 20 \mathrm{~cm}$ soil layers, the DH treatment was significantly higher than the other treatments. Each of the five cropping patterns had a significant effect on soil organic carbon distribution $(P<0.05)$. Within the $5-10 \mathrm{~cm}$ soil layer, there was a significant effect $(P<0.05)$ between the four intercropping plantings and the $C K$ treatment, while there was a non-significant effect $(P>0.05)$ on soil organic carbon distribution in the DB and DH treatments. Soil ammonium $\mathrm{N}$ content showed a decreasing trend with increasing soil depth (Figure 5), with the highest content in the DJ treatment and the lowest in the CK treatment. In the depth range of $0-5 \mathrm{~cm}$ soil layer, all four intercropping treatments were significantly higher than monoculture, among which there was a non-significant difference between DH treatment and DB treatment $(P>0.05)$, in 5-10 cm soil layer, there was a non-significant difference between DM treatment and DB treatment $(P>0.05)$, while in $10-15 \mathrm{~cm}$ soil layer, there was a significant effect between intercropping treatment and monoculture treatment $(P<0.05)$. 
In 10-15 cm soil layer, the DM and DH treatment had non-significant effects, each intercropping treatment had significant effects with CK treatment $(P<0.05)$. Within the 15-20 $\mathrm{cm}$ soil layer, the soil ammonium nitrogen content of the five cropping patterns did not vary significantly, DB, DH treatment and CK treatment had no significant difference, but there was a significant difference with each intercropping treatment. Soil nitrate $\mathrm{N}$ content was generally highest in the DJ treatment and lowest in the CK treatment at different soil depths (Figure 5). In the $0-5 \mathrm{~cm}$ soil layer, five cropping patterns were significantly different $(P<0.05)$. Within $5-10 \mathrm{~cm}, 10-15 \mathrm{~cm}$ soil layer, the DM treatment was not significantly different from the $C K$ treatment $(P>0.05)$. In the $15-20 \mathrm{~cm}$ soil layer, there was a significant difference between DJ treatment and CK treatment, while there was a non-significant difference between DM treatment and DB treatment $(P>0.05)$.

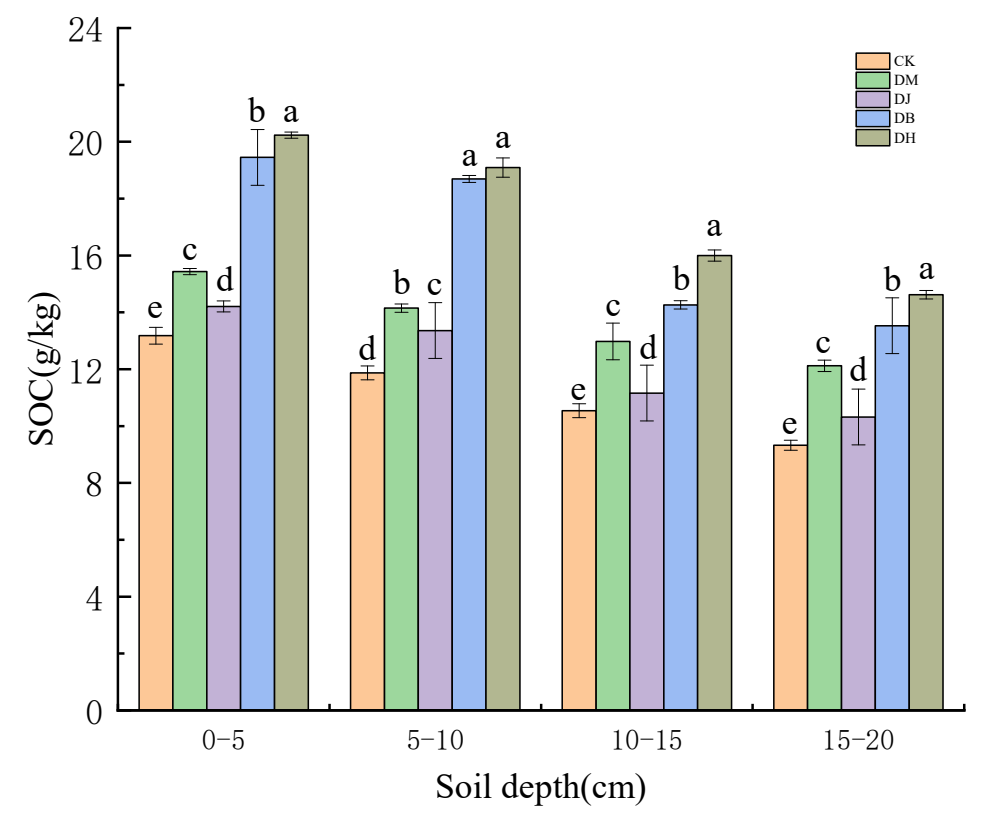

Figure 4. Distribution changes of soil organic carbon content in different treatments.
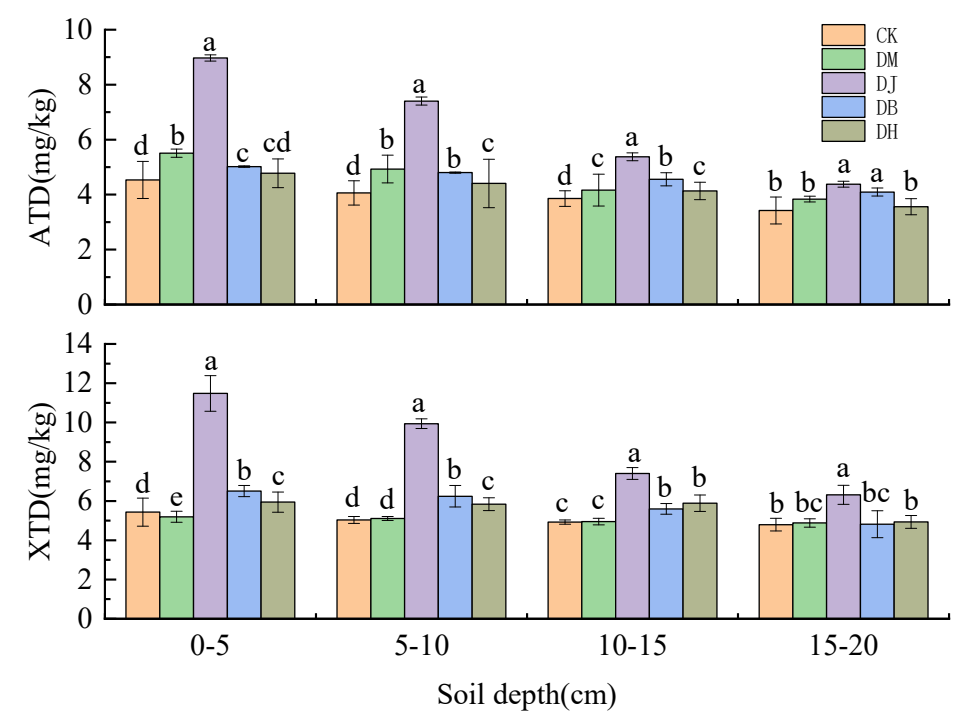

Figure 5. Distribution changes of soil nitrogen in different treatments. 


\subsection{Study on the change of soil particle composition by intercropping}

It can be seen that the soil particle composition in this study area is mainly composed of sand grains(Figure 6), followed by powder grains, with the smallest clay grains. Soil coarse sand $(0.2 \sim 2 \mathrm{~mm})$ and fine sand $(0.02 \sim 0.2 \mathrm{~mm})$ had higher contents, $55.28 \%-68.78 \%$ and $13.56 \%-18.68 \%$, with mean contents of $61.99 \%$ and $16.28 \%$, respectively. The mean value of soil powder grains $(0.002-0.02 \mathrm{~mm})$ was at $13.22 \%$. Soil clay particles $(<0.002 \mathrm{~mm})$ had the lowest content with a mean value of $7.62 \%$.

It shown that the intercropping pattern had different significant effects on the distribution of soil particle content in different depths of the soil layer(Figure 6). The distribution of soil particle content in each treatment mainly showed coarse sand $>$ fine sand $>$ powder > clay particles. In the distribution of soil clay grain content, the highest clay grain content was in DB treatment and the lowest in CK treatment in different soil depth range, among which the difference between $\mathrm{DH}$ treatment and other treatments was not significant $(P>0.05)$ in $0 \sim 5 \mathrm{~cm}$ soil layer, in $5 \sim 10 \mathrm{~cm}$ soil layer, all treatments were significantly different $(P<0.05)$. In 10 15 cm soil layer, the difference between $C K$ treatment and other treatments was not significant $(P>0.05)$. Within the $15-20 \mathrm{~cm}$ soil layer, the DM treatment was not significantly different from the other treatments $(P>0.05)$. In the distribution of soil fine sand content, DB treatment was the highest and DH treatment was the lowest. There was no significant effect $(P>0.05)$ between DB treatment and other treatments within $0 \sim 5 \mathrm{~cm}$ soil layer. A significant effect $(P<0.05)$ existed between treatments in $5 \sim 10 \mathrm{~cm}$, $10 \sim 15 \mathrm{~cm}$ and $15 \sim 20 \mathrm{~cm}$. The clay grain content was highest in CK treatment and lowest in DB treatment in different soil depth ranges. In the distribution of soil coarse sand content, each treatment had a significant effect $(P<0.05)$ between $5 \sim 10 \mathrm{~cm}, 10 \sim 15 \mathrm{~cm}$ and $15 \sim 20 \mathrm{~cm}$ of soil layer, while DH treatment was not significantly different from other treatments within $0 \sim 5 \mathrm{~cm}$ of soil layer.
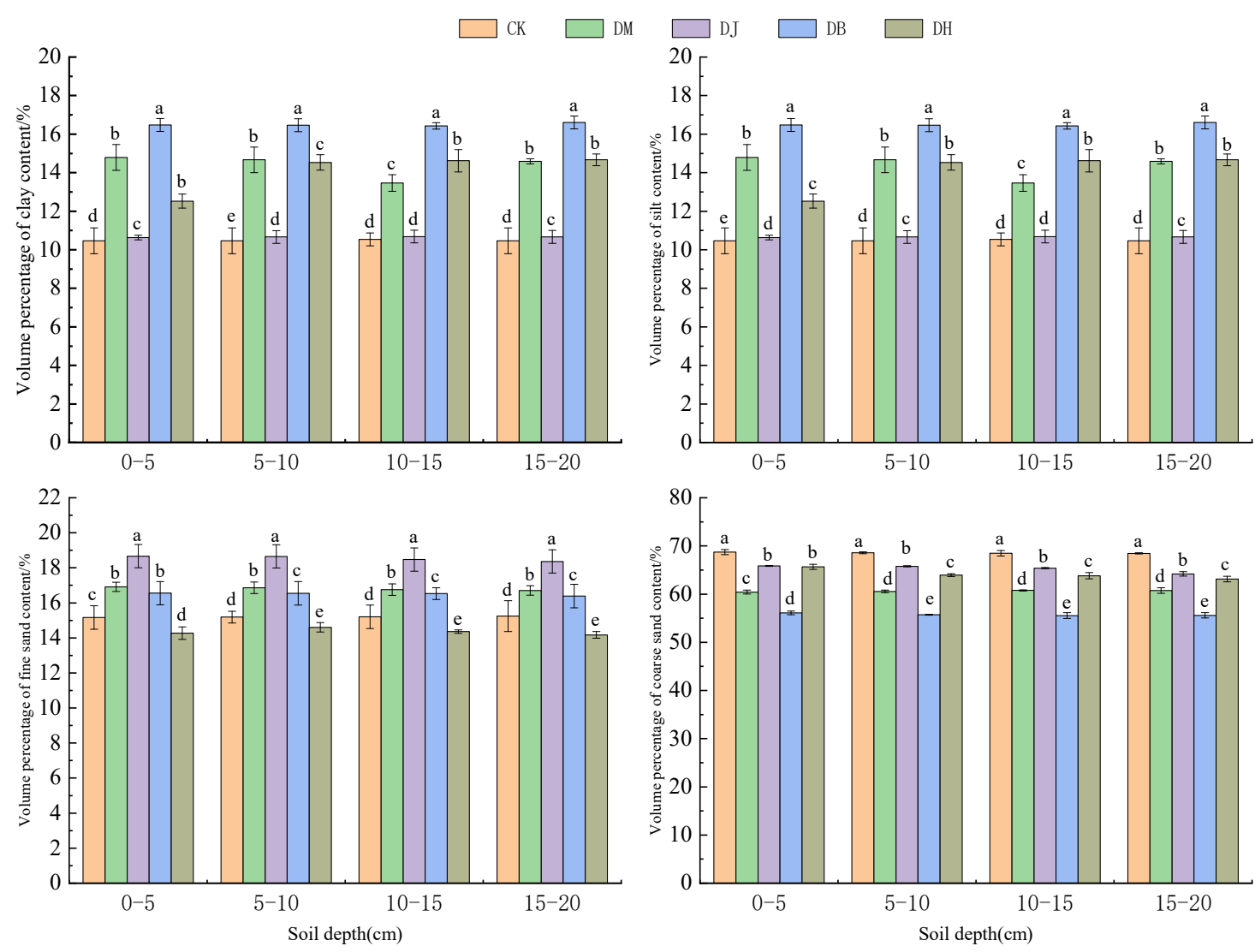

Figure 6. Changes in the distribution of soil particles in different treatments. 


\subsection{Study on the change of soil fractal dimension by intercropping}

The soil fractal dimension in the study area ranged from 2.60 to 2.77 (Figure 7). In the $0-5 \mathrm{~cm}, 5-10 \mathrm{~cm}$, and $10-15 \mathrm{~cm}$ soil layers, the planting pattern had a significant effect on the soil fractal dimension $(P<0.05)$. There were significant differences between planting patterns $(P<0.05)$, with $\mathrm{DB}>\mathrm{DM}>\mathrm{DH}>\mathrm{CK}>\mathrm{DJ}$, while in the $15-20 \mathrm{~cm}$ soil layer, the $\mathrm{DH}$ treatment was not significantly different from the DB treatment $(P>0.05)$. The soil fractal dimension was $\mathrm{DB}>\mathrm{DM}>\mathrm{DH}>\mathrm{DJ}>\mathrm{CK}$. In the $15-20 \mathrm{~cm}$ soil layer, the $\mathrm{DH}$ treatment was not significantly different from the DB treatment $(P>0.05)$. The soil fractal dimension was $\mathrm{DB}>\mathrm{DM}>\mathrm{DH}>\mathrm{DJ}>\mathrm{CK}$.

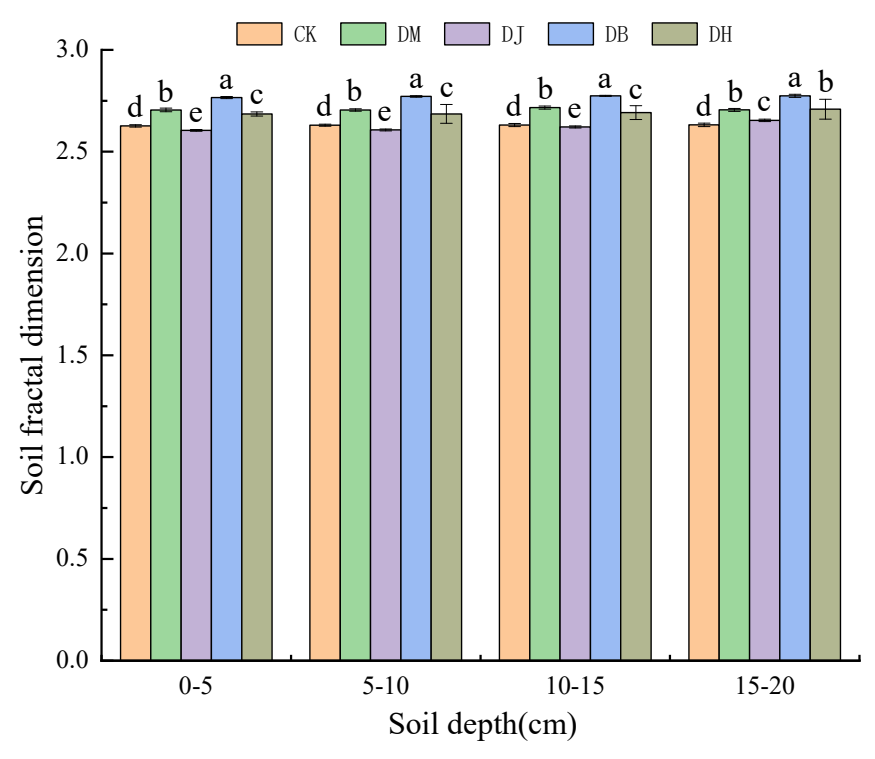

Figure 7. Changes of soil fractal dimension in different treatments.

\subsection{Study on the change of soil properties by intercropping}

\subsubsection{Correlation variation of particle size and fractal dimension}

From (Figure 8), it can be seen that soil clay content showed a linear positive correlation with fractal dimension $\left(\mathrm{R}^{2}=0.9678, \mathrm{r}=0.9660\right)$. The soil fractal dimension was linearly correlated with the soil powder content $\left(\mathrm{R}^{2}=0.9119, \mathrm{r}=0.9549\right)$. Soil fine sand content showed a linear negative correlation with soil fractal dimension $\left(R^{2}=0.0304, r=-0.1744\right)$. Soil coarse sand content showed a linear negative correlation with soil fractal dimension $\left(\mathrm{R}^{2}=0.8656, \mathrm{r}=-0.9303\right)$. The best correlation was found with $<0.002 \mathrm{~mm}$ soil particle content. The higher the content of fine soil particles, the higher the fractal dimension and vice versa. From (Figure 8), it is apparent that $<0.02 \mathrm{~mm}$ particle size is the critical particle size that determines the fractal dimension of the soil in the planting pattern. Because the higher the volume content of particles with a particle size of $<0.02 \mathrm{~mm}$, the greater the value of the fractal dimension, and the higher the volume content of particles with a particle size of $>0.02 \mathrm{~mm}$, the smaller the fractal dimension. In summary, soil volume fractal dimension showed a significant positive correlation with the volume content of fine soil particles $(>0.02 \mathrm{~mm})$ and a negative correlation with the volume content of coarse particles $(<0.02$ $\mathrm{mm}$ ). Because the smaller the particles, the finer the texture, the more difficult the formation of soil structure. Moreover, the finer the texture, the more microscopic pores of the soil, the more complex the internal structure with higher fractal dimension $[19,20]$. 

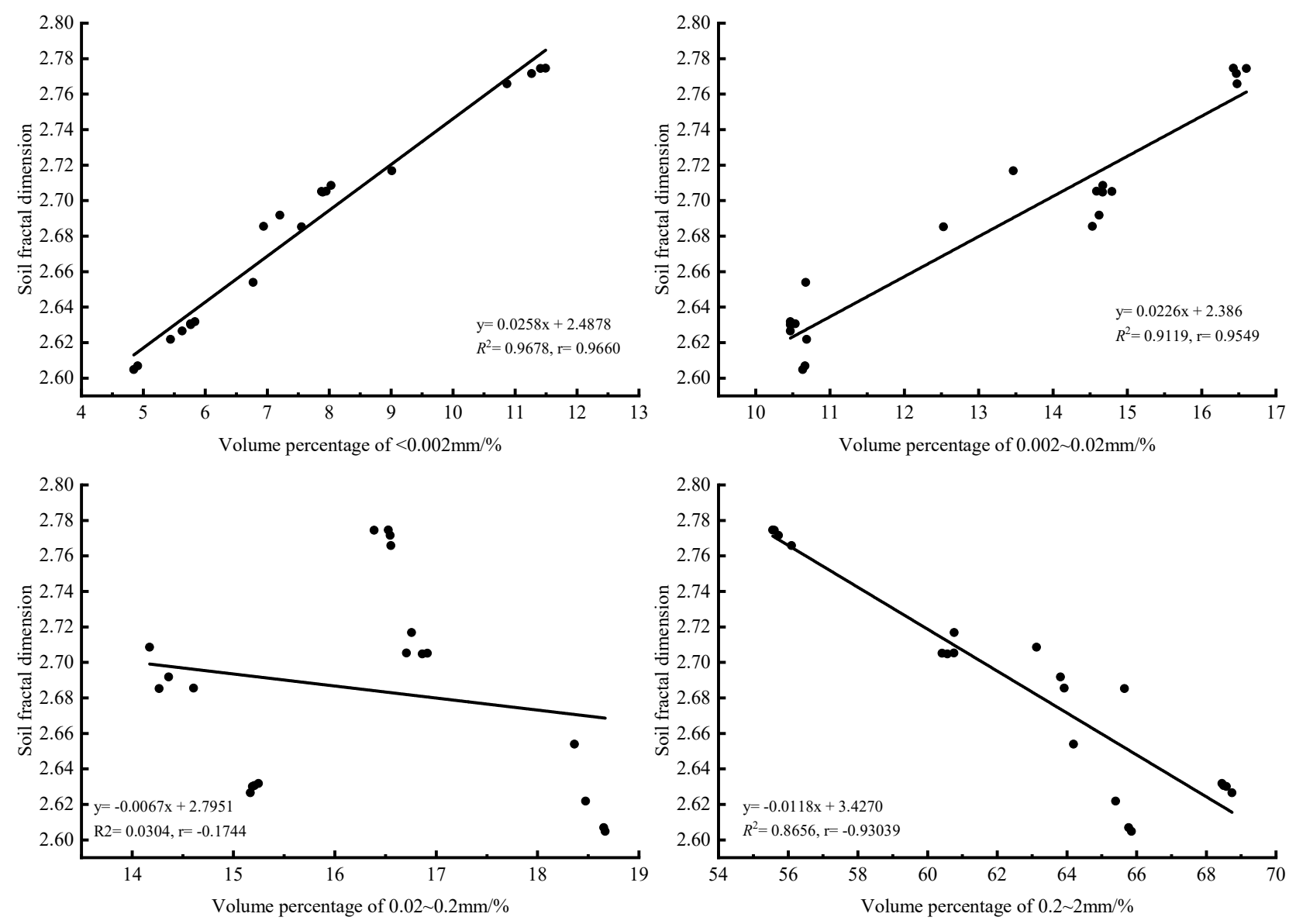

Figure 8. Correlation changes between soil particle size and fractal dimension.

\subsubsection{Changes in the correlation of soil indicators under intercropping}

From (Figure 9), it can be seen that soil fractal dimension has a significant positive correlation with soil fine particle volume content, a significant negative correlation with soil coarse particle content, while there is no correlation with soil physicochemical properties. Soil coarse particle volume content showed a significant negative correlation with fine particle volume content, without significant correlation with soil physicochemical properties. There was a significant correlation between soil capillary porosity and soil water content and chemical properties, with significant correlation between soil water content. Previous studies have shown that soil pore structure is complex, pore space is highly variable, whereas irregular pore morphology can enhance soil saturated water content, increase total soil porosity and improve soil water content. 


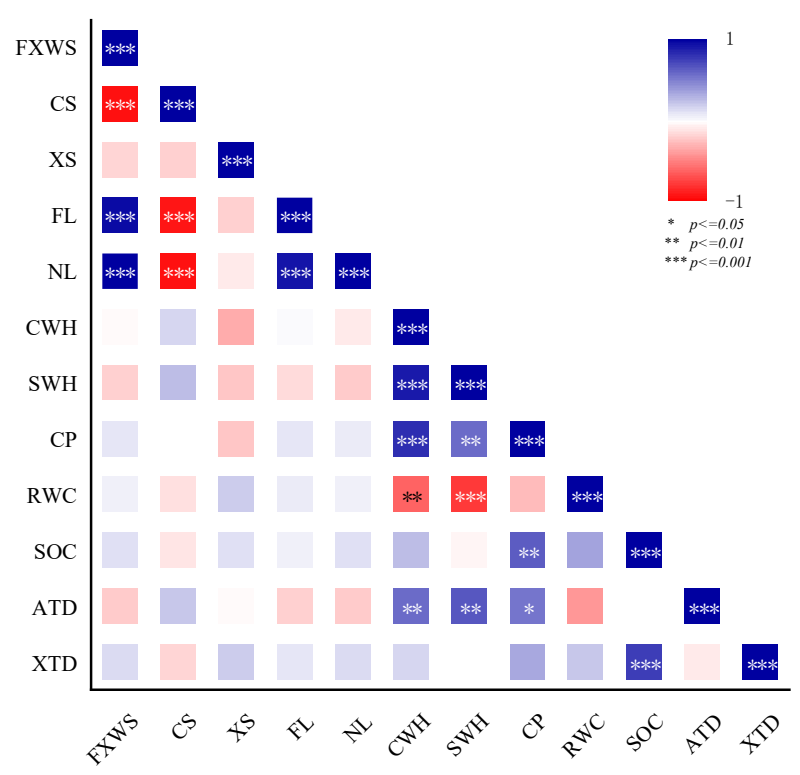

Figure 9. Correlation changes of soil physical and chemical properties and fractal dimension.

\subsubsection{Changes in principal component analysis of soil indicators under intercropping}

Principal component analysis was used to continue the analysis of the relationship between intercropping on soil particle composition, fractal dimension and physicochemical properties. Two common factors with eigenvalues $<3$ were extracted, the accumulated contribution of common factors reached $63.1 \%$, fulfilling the requirements of principal component analysis. As shown in (Figure 10), the 1st principal component was strongly correlated with soil fractal dimension, soil sand content, soil powder content and soil clay content. Hence, the 1st principal component mainly reflects the influence of soil fractal dimension and soil particle content with planting pattern. The 2nd principal component is strongly correlated with soil capillary water holding capacity, saturated water content, capillary porosity and relative water content, which mainly reflect the influence of soil physical properties and cropping patterns. 2 principal components reflect the driving factors of different cropping patterns and soil environmental changes from different aspects, respectively. 


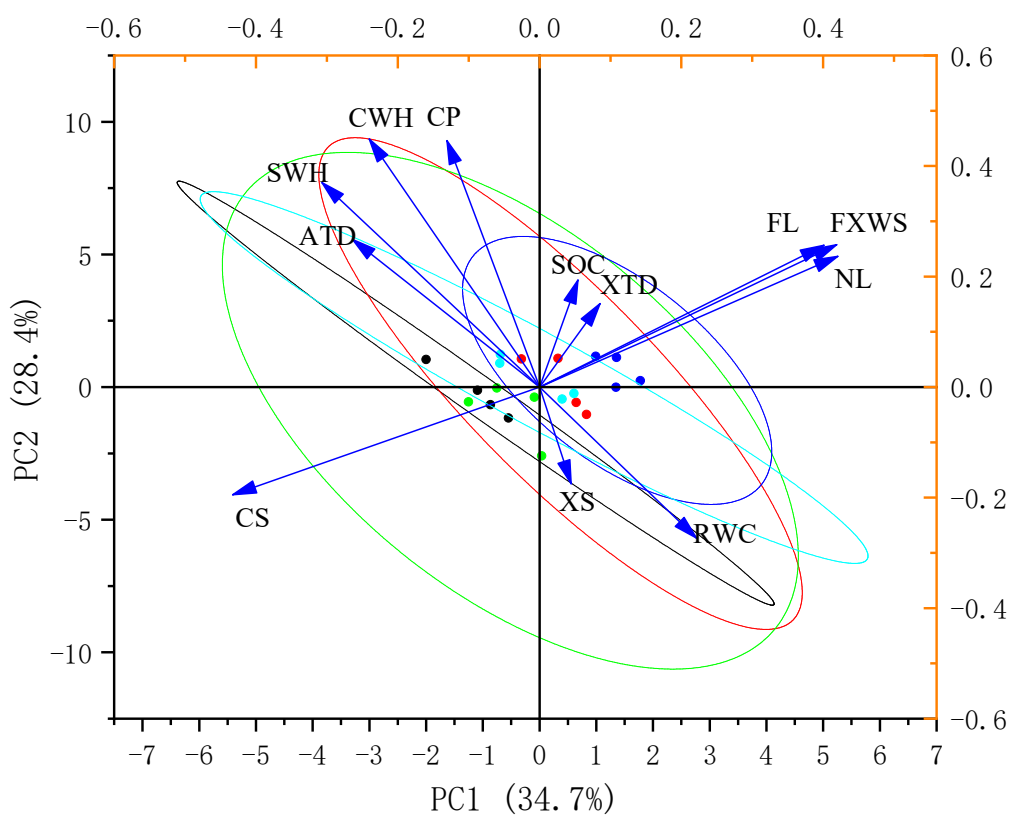

Figure 10. Principal component analysis of soil indexes under different treatments.

\section{Discussion}

\subsection{Study on the characteristic changes of soil particle size and fractal dimension}

The correlation between soil fractal dimension and percent volume of fine particles and soil nutrients is high, which can reflect the degree of surface wind erosion and soil structure [21,22], scientifically evaluating the degree of soil consolidation capacity and the effect of intercropping on soil environment improvement. The results of this study showed that the soil clay content of $S$. miltiorrhiza intercropping was significantly higher than that of monoculture, and the soil sand content of S. miltiorrhiza monoculture was significantly higher than that of intercropping. The improvement of soil structural properties was more significant in S. miltiorrhiza intercropped with L. perenne compared with intercropped with $M$. sativa, as L. perenne plants have more tillers and large root systems, which save fine particulate matter from blowing and effectively intercept atmospheric dust materials during their growth, and the redistribution of soil particle composition can be significantly different in different intercropped plantings, thus indirectly affecting soil structure and nutrient characteristics [23]. There are significant differences in the single morphological structure of the two landscape trees in Salix intercropping, especially between the plant height and branch sparseness, such as the juvenile greenery seedlings of Sophora japonica, a shrub form with many twisted branches and slender twigs. perennial trees of Lagerstroemia indica, with well-developed, dense, soft and pendulous branches and a well-developed deep root system, due to the differences in the external structure resulting in different soil particle composition for the deposition of dusty material to the surface in the area, resulting in differences in soil fractal dimension at 0-20 cm soil depth under different intercropping types, and some variability among different species in the same soil layer, resulting in different soil nutrient contents. The soil fine particulate matter of intercropped Lagerstroemia indica was significantly larger than that of intercropped Sophora japonica, indicating that the differences in the height, crown width, branch sparseness and root development of individual plants caused different intercropping methods on the wind-fixing effect and soil environment improvement ability, which affected the composition of soil particles. 


\subsection{Study on the changes of planting pattern on the characteristics of soil physicochemical} properties

Soil water holding capacity is the ability of soil to hold and retain water, which is an important physical property of soil. When precipitation or irrigation water enters the soil, it will be affected by the combined effect of molecular gravity, capillary force and gravity of soil particles, thus the moisture will soak, move and be held in the soil through the soil pores. Soil water is a key factor affecting the physiological structure and function of crops in the karst areas [24]. Studies have shown that soil water holding capacity is related to the nature of the soil itself [25], it is mainly held by the adsorption of water by soil particles and capillary forces in soil capillary pores, so soil surface area and soil pore space directly determine soil water retention [26], while soil physical and chemical properties such as soil bulk, texture, and organic matter content mainly affect soil by influencing pore condition and specific surface area to water-holding capacity. Soil water holding capacity is closely related to organic carbon content [27] and is influenced by factors such as soil particle distribution and capacitance, where soil particles affect water holding capacity by influencing pore distribution $[28,29]$. As can be seen from Figure 7, soil water content in general shows a negative correlation with increasing soil particles in the same soil depth, which decreases with increasing soil depth, showing different differential changes in soil water content between intercropping and monoculture. Intercropping planting in areas with coarse soil particles in karst rocky desertification, the ground cover gradually increases, the accumulation of dead leaves and the retention of plant leaves at different levels, the atmospheric precipitation is effectively absorbed by plants and the retained water increases, thus increasing the soil water holding capacity. Ling [30] showed that intercropping can greatly improve the soil surface cover as well as increase the amount of soil root distribution, which can make the soil surface less subject to erosion by water and wind, more humus content such as organic matter and other plant residues in the soil, as well as higher soil water holding capacity. In this study, the saturated water content of soil was significantly higher in monoculture than in intercrop at different soil depths, indicating that intercrop crops have greater uptake of soil water than monoculture. The correlation of soil water holding capacity with organic carbon and ammonium nitrogen was significant, but not with nitrate nitrogen, indicating that soil water holding capacity of each soil layer in the study area was mainly influenced by soil particle distribution, organic carbon and ammonium nitrogen factors.

Soil organic carbon content is an important indicator of soil nutrient content [31]. The variation of its content is not only influenced by the parent soil-forming material [32], but also closely related to planting methods, tillage practices, ground cover conditions and plant root distribution characteristics [33 35]. The influence of plant roots on soil organic carbon is mainly through root penetration, entanglement and network sequestration to influence the physical properties of the soil, which in turn improves the soil's resistance to erosion, infiltration, shear capacity, ability to contain water and nutrients [36]. In the karst areas, the soil layer is shallow and thin, some areas have coarse soil particles mainly in sandy loam, the density of vegetation root volume generally decreases with the increase of soil depth, which makes soil organic carbon decrease with the increase of soil depth. In this study, we found that the soil organic carbon content of four intercrop plantings was significantly higher than that of monoculture plantings. The soil organic carbon content of intercropped landscape trees was again significantly higher than that of intercropped forage. Cong [37] also found that the soil organic carbon content of the intercrop pattern was significantly higher than that of the monoculture treatment. The reason for this is that, in addition to the influence of soil particles, it is likely to be related to the ground cover condition and plant root distribution characteristics, the intercropping pattern has a significant biomass and yield advantage, the root biomass is significantly higher than the monoculture treatment, and the residual carbon is easily imported to the soil through the root system [38,39]. on the other hand, in the intercropping pattern, there will be interaction between the roots of different crops, promoting the growth of root secretion. On the 
other hand, in the intercropping pattern, there is an interaction between the roots of different crops, which promotes the growth of root secretions, increases the activity of soil microorganisms, and soil organic carbon is sequestered and mineralized [40].

Research shows that nitrogen, as an essential nutrient for plants, is an important factor affecting plant growth and development, mainly by regulating photosynthesis, respiration and root uptake of mineral elements in plants. Ammonium nitrogen and nitrate nitrogen, as the main forms of inorganic nitrogen absorbed and utilized by plants, play an important role in the process of plant growth and development [41]. Nitrate nitrogen can promote photosynthetic carbon assimilation and sucrose accumulation in plants, it has a positive effect on stem and leaf growth and regulation of leaf aging, while ammonium nitrogen can promote the accumulation of starch in plant leaves and improve the photosynthetic capacity of plants, but its content should be kept within a reasonable range, and too much can lead to metabolic disorders and "ammonium poisoning" in plants[42,43]. In this study, the nitrate and ammonium nitrogen contents in the surface layer $(0-20 \mathrm{~cm})$ of the soils of the four intercropping patterns were significantly higher than those of monoculture, which was mainly due to the fact that nitrate and ammonium nitrogen in the surface layer of monoculture were not easily leached by soil adsorption, and soil nitrogen was not easily leached by intercropping due to the influence of the root system during growth, which indicated that intercropping could not only alleviate the rapid leaching of nitrogen from the surface layer, but also increase soil adsorption of nitrogen and improve soil nitrogen utilization. This indicates that intercropping can not only alleviate the rapid loss of nitrogen from the surface layer, but also increase soil nitrogen sorption and improve soil nitrogen utilization. In the present study, the soil nitrogen content of $M$. sativa intercropped with $S$. miltiorrhiza was significantly higher than that of other intercrops and monocultures, which is similar to the findings of Liu et al [44], who found that the soil ammonium nitrogen content of alfalfa was higher than that of other crops. On the one hand, it may be related to the nitrogen fixation by the roots of $M$. sativa, on the other hand, the soil water content of intercropped M. sativa was lower than other treatments, which reduced the leaching of nitrogen from the soil surface layer and enhanced the mineralization, thus making the soil nitrogen content higher than other treatments.

\section{Conclusions}

Intercropping planting occupies an important position in the stone desertification agroforestry ecosystem by reasonably utilizing the ecological functions of different vegetation and coordinating the relationship between crops and the environment. Principal component analysis and correlation analysis showed that the changes of intercropping on soil water content and capillary porosity were inconsistent, the soil water content and capillary porosity were higher in forest intercropping $S$. miltiorrhiza than in forage intercropping, S. miltiorrhiza intercropping could effectively improve the soil fine particle matter, the more fine sand content the greater the soil fractal dimension, indicating that the fractal dimension could well reflect the degree of change of soil particle size distribution under intercropping methods. Among the four intercropping methods, the soil fine particulate matter content was the highest in the forest intercropping of S. miltiorrhiza, the soil carbon and nitrogen content was significantly greater in the intercropping than in the monoculture, the soil total carbon content was the best in the forest intercropping, while the soil nitrogen content was the highest in the legume forage intercropping of S. miltiorrhiza. This study is only a preliminary study to compare the ecological effects of four kinds of $S$. miltiorrhiza species under one year of compound planting growth, and it is a single analysis of the soil-plant relationship without the long-term dynamic change process and the influence of other ecological measures. Therefore, we recommend combining the physiological characteristics conditions of different plants, reasonable selection of crop species and management methods, and long-term monitoring. Intercropping is used as a sustainable development tool combined with other agroforestry development models and eco- 
logical restoration measures in order to promote the structure and function of the damaged agroforestry ecosystem in stone desertification, promoting ecological restoration and economic development in stone desertification areas.

Author Contributions: Qinqin Xu: Conceptualization, Methodology, Writing - review \&editing, Software, Validation. Kangning Xiong: Conceptualization, Visualization, Supervision, Investigation. Yongkuan Chi: Data curation, Methodology, Writing - review \& editing, Supervision.

Funding: Please add: This research was funded by the World Top Discipline Program of Guizhou Province: Karst Ecoenvironment Sciences (No.125 2019 Qianjiao Keyan Fa), the Key Project of Science and Technology Program of Guizhou Province: Poverty Alleviation Model and Technology demonstration for Ecoindustries Derivated from the karst desertification control (No. 54112017 Qiankehe Pingtai Rencai).

Conflicts of Interest: The authors declare no conflict of interest.

\section{References}

1. Xiong, Kangning.; Chen Qiwei. Discussion on karst rocky desert evolution trend based on ecologically comprehensive treatment. Caisologica Sinica, 2010, 29, 50-56. [CrossRef]

2. Jiang, Z.C.; Lian, Y.Q.; Qin, X.Q. Rocky desertification in southwest China: impacts, causes, and restoration. Earth-Science Reviews. 2014, 132, 1-12.[CrossRef]

3. Xiong, K.N.; Li, J.; Long, M.Z. Features of Soil and Water Loss and Key Issues in Demonstration Areas for Combating Karst Rocky Desertification. Acta Geographica Sinica. 2012, 67, 878-888. [CrossRef]

4. Sheng, M. Y.; Liu, Y.; Xiong, K.N. Response of soil physical-chemical properties to rocky desertification succession in South China Karst. Acta Ecologica Sinica. 2013, 33, 6303-6313. [CrossRef]

5. Li, Y.B.; Shao, J.A.; Yang, H.; Bai, X.Y. The Relations Between Land Use and Karst Rocky Desertification in A Typical Karst Area, China. Environ Geol. 2009, 57, 621-627. [CrossRef]

6. Tom, G. Formation of mineral-mineral and organo-mineral composite building units from microaggregate-forming materials including microbially produced extracellular polymeric substances. Eur J Soil Sci. 2019, 70, 604-615.

7. Yin, W.; Chai, Q.; Zhao, C. Water utilization in intercropping: A review. Agr Water Manage. 2020, 241, 335-348. [CrossRef]

8. Amundson, R.; Berhe, A. A.; Hopmans, J. W. Soil and human security in the 21st century. Science. 2015, 348, 647-647. [CrossRef]

9. Zhang, J.Y.; Zhou, F.; Su, W.C. Study on The Mode of Agricultural Modernization Transformationand Development of Karst Peak Cluster Depression in Southwest China? Chinese Journal of Agricultural Resources and Regional Planning. 2020, 41, 5764. [CrossRef]

10. Chen, Q.W.; Lu, S.X.; Xiong, K.N. Coupling analysis on ecological environment fragility and poverty in South China Karst. Environ Res. 2021, 201, 111650. [CrossRef]

11. Wang, L.J.; Wang, P.; Sheng, M.Y. Stoichiometric characteristics of soil nutrient elements and its influencing factors in typical karst rocky desertification ecosystems, Southwest China. Acta Ecologica Sinica. 2018, 38, 6580-6593. [CrossRef]

12. Su, Y.Z.; Zhao, H.L. Fractal features of soil particle size distribution in the desertification process of the farmland in Horqin Sandy Land. Acta Ecologica Sinica. 2004, 24, 71-74. [CrossRef]

13. Long, J.; Li, J.; Deng, Q.Q. Soil Properties and Fractal Features in the Rocky Desertification Process of Karst Regions, Guizhou Province. Chinese Journal of Soil Science. 2006, 37, 635-639. [CrossRef]

14. Xiong, B.; Wang, J.L.; Zhang, T.W. Study on volume fractal features of soil particle under different land use types in southeast karst mountain of Chongqing. Carsologica Sinica, 2011, 30, 295-301. [CrossRef]

15. Li, X.N.; Xiong, K.N.; Chen, H. Biodiversity and world heritage values of Shibing dolomite karst area in Qiandongnan. Journal of Guizhou Normal University (Natural Sciences). 2010, 28, 13-18. [CrossRef]

16. He, C.; Zeng, C.; Xiao, S.Z. Preliminary Study on Hydrological and Hydrochemical Regime of a Typical Humid Subtropical Dolomite Catchment, A Case Study in the Huangzhou River Basin, Shibing County, Guizhou Province. Earth and Environment. 2020, 48, 279-293. [CrossRef]

17. Liu, Q.; Gu, Z.F.; Lu, Y.R. The Experimental Study of Dolomite Dissolution and Pore Characteristics in Shibing, Guizhou. Acta Geoscientia Sinica. 2015, 26, 413-418. [CrossRef]

18. Tyler, S.W.; Wheatcraft, S.W. Application of fractal mathematics to soil water retention estimation. Soil Sci Soc Am J. 1989, 53,987-996. [CrossRef]

19. Jia, X.H.; Li, X.R.; Zhang, J.G. Spatial heterogeneity analysis of fractal dimension of soil particle for Ammopiptanhus mongolicus shrub. Acta Ecologica Sinica. 2006, 26, 2827-2833. [CrossRef]

20. Hu, Y.F.; Liu, J.Y.; Zhuang, D.F. Fractal Dimension of Soil Particle Size Distribution Under Different Land Use / Land Coverage. Acta Pedologica Sinica. 2005, 42, 336-336. [CrossRef]

21. Xia, D.; Deng, Y.S.; Wang, S.L. Fractal features of soil particle-size distribution of different weathering profiles of the collapsing gullies in the hilly granitic region, south china. Nat Hazards. 2015, 79, 455-478. [CrossRef] 
22. Zhang, S.R.; Deng, L.J.; Zhou, Q. Fractal Dimensions of Particle Surface in The Plowed Layers and Their Relationships with Main Soil Properties. Acta Pedologica Sinica. 2002, 39, 221-226. [CrossRef]

23. Wang, D.; Fu, B.J.; Chen, L.D. Fractal analysis on soil particle size distributions under different land-use types: a case study in the loess hilly areas of the Loess Plateau, China. Acta Ecologica Sinica. 2007, 27, 3081-3089. [CrossRef]

24. Yuan, C.J.; Xiong, K.N.; Rong, L. Research Progress on the Biodiversity during the Ecological Restoration of Karst Rocky Desertification. Earth and Environment. 2021, 49, 1-10. [CrossRef]

25. Ulusal, A.; Varol, E. A.; Bruckman, V. J.; Uzun, B. B. Opportunity for sustainable biomass valorization to produce biochar for improving soil characteristics. Biomass Convers Bior. 2021, 11, 67-69. [CrossRef]

26. Somasundaram, J.; Salikram, M.; Sinha, N. K.; Mohanty, M.; Chaudhary, R. S.; Dalal, R. C.; Mitra, N. G.; Blaise, D.; Coumar, M. V.; Hati, K. M.; Thakur, J. K.; Neenu, S.; Biswas, A. K.; Patra, A. K.; Chaudhari, S. K. Conservation agriculture effects on soil properties and crop productivity in a semiarid region of India. Soil Res. 2019, 57, 187-199. [CrossRef]

27. Abid, M.; Lal, R. Tillage and drainage impact on soil quality: II. Tensile strength of aggregates, moisture retention and water infiltration. Soil Till Res. 2009, 103, 364-372. [CrossRef]

28. Auge, R. M., Stodola, A. J. W., Tims, J. E., 2001. Moisture retention properties of a mycorrhizal soil. Plant Soil. 230 , 87-97. [CrossRef]

29. Gube, R. A.; Pachepsky, Y.; Shein, E. Soil Aggregates and Water Retention. Developments in Soil Science. 2004, 30, 143-150. [CrossRef]

30. Ling, Q.; Zhao, X.N.; Gao, X.D. Effects of inter-row economic crop planting on soil moisture in a rain-fed jujube orchard in loess hilly region, China. Chinese Journal of Applied Ecology. 2016, 27, 504-510. [CrossRef]

31. Wang, C. T.; Long, R. J.; Wang, Q.L. Changes in soil organic carbon and microbial biomass carbon at different degradation successional stages of alpine meadows in the Headwater Region of Three Rivers in China. Chinese Journal of Applied \& Environmental Biology. 2008, 14, 225-230. [CrossRef]

32. Pan, C.X.; LI, Y.Y.; Peng, Y. Soil water holding capacity under four typical ecosystems in Wuyunjie Nature Reserve of Hunan Province. Acta Ecologica Sinica. 2012, 32, 538-547. [CrossRef]

33. Zhang, J.H.; Li, G.D.; Nan, Z.R. Research on soil particle size distribution and its relationship with soil organic carbon under the effects of tillage in the Heihe oasis. Geogr Res-Aust. 2012, 31, 608-618. [CrossRef]

34. Zotarelli, L.; Alves, B.J.R. Urquiaga S, et al. Impact of tillage and crop rotation on light fraction and intra-aggregate soil organic matter in two Oxisols. Soil Till Res. 2007, 95, 196-206. [CrossRef]

35. Techen, A.K.; Helming, K.; Brüggemann, N. Soil research challenges in response to emerging agricultural soil management practices. Adv Agron. 2020, 161, 179-240. [CrossRef]

36. Wang, K. Effects of plant roots on soil anti-erosion. Soil and Environmental Sciences. 2001, 10, 250-252. [CrossRef]

37. Cong, W.F.; Hoffland, E.; Li, L. Intercropping enhances soil carbon and nitrogen. Global Change Biol. 2015, 21, 1715-1726. [CrossRef]

38. Brady, N.C.; Weil, R.R. The nature and properties of soils, 14th edition[M]. Pearson Education Inc. 2008.

39. Yang, C.H.; Chai, Q.; Huang, G.B. Root distribution and yield responses of wheat/maize intercropping to alternate irrigation in the arid areas of northwest China. Plant Soil Environ. 2010, 56, 253-262. [CrossRef]

40. Fu, X.P.; Wu, F.Z.; Wu, X. Advances in the mechanism of improving crop mineral nutrients in intercropping and relay intercropping systems. Plant Nutrition and Fertilizer Science. 2016, 22, 525-535. [CrossRef]

41. Bruun, S.; Luxhoi, J.; Magid, J. A nitrogen mineralization model based on relationships for gross mineralization and immobilization. Soil Biol Biochem. 2006, 38, 2712-2721. [CrossRef]

42. Yurova, A.; Wolf, A.; Sagerfors, J. Variations in net ecosystem exchange of carbon dioxide in a boreal mire: Modeling mechanisms linked to water table position. J Geophys Res-Biogeo, 2015, 112, 245-252. [CrossRef]

43. Scheible, W.R.; Gonzalezfontes, A.; Lauerer, M. Nitrate acts as a signal to induce organic acid metabolism and repress starch metabolism in tobacco. Plant Cell. 1997, 9, 783-798. [CrossRef]

44. Liebig, M. A.; Hendrickson, J. R.; Berdahl, J. D. Response of soil carbon and nitrogen to transplanted alfalfa in North Dakot. Can J Soil Sci. 2010, 90, 523-526. [CrossRef] 